\title{
Optimal delivery of male breast cancer follow-up care: improving outcomes
}

\author{
This article was published in the following Dove Press journal: \\ Breast Cancer: Targets and Therapy \\ 23 November 2015 \\ Number of times this article has been viewed
}

\section{Raina M Ferzoco \\ Kathryn J Ruddy \\ Department of Oncology, Mayo Clinic, Rochester, MN, USA}

\begin{abstract}
Male breast cancer is a rare disease. There are limited data to inform optimal treatment and follow-up strategies in this population. Currently, most follow-up guidelines are drawn from the vast literature on female breast cancer, despite the fact that male breast cancer has unique biological characteristics. In this review, we discuss clinical characteristics of male breast cancer as well as current best practices for long-term care with a focus on surveillance, screening, and treatment-related symptom management in male breast cancer survivors.
\end{abstract}

Keywords: male breast cancer, follow-up, surveillance, screening

\section{Introduction}

Male breast cancer is a rare disease, comprising $1 \%$ of all breast cancer diagnoses and $0.25 \%$ of cancer diagnoses in men in the US. ${ }^{1,2}$ In 2015 , it is estimated that 2,350 American men will be diagnosed with breast cancer and that 440 will die of the disease. ${ }^{3}$ Known risk factors for male breast cancer include genetic mutations (most notably, $B R C A 2$ ), radiation exposure, increasing age, family history, and conditions that alter the estrogen/androgen balance, including Klinefelter syndrome. ${ }^{4-18}$ However, little is known regarding optimal treatment and follow-up strategies for these patients. Currently, most male breast cancer care algorithms are extrapolated from the treatment and follow-up of female breast cancer patients, and data are particularly lacking regarding postcancer surveillance for male breast cancer survivors. In this manuscript, we review what is known about the clinical characteristics and treatment patterns seen in male breast cancer as a background for our discussion of best practices in surveillance, genetic testing, and management of side effects in male patients.

\section{Clinical characteristics and treatments}

Cardoso et al recently reported the initial results of the EORTC10085/TBCRC/BIG/ NABCG International Male Breast Cancer Program retrospective analysis, utilizing the largest collection of male breast cancer clinical characteristics and biological samples to date $(\mathrm{N}=1,483) .{ }^{19}$ This study confirmed previous research showing that male breast cancer has different biological characteristics than female breast cancer, with higher rates of hormone receptor positivity, older age at presentation, and higher proportion of nodal disease at presentation. ${ }^{2,20,21}$ In this large international cohort, only $10 \%$ of patients were 50 years or younger at diagnosis, the median age at diagnosis was 68 years, and $45 \%$ had node positive disease at presentation.

The majority of men with early stage disease underwent modified radical mastectomy ( $96 \%$ ), but $\sim 50 \%$ of patients with node positive disease (who could potentially benefit
Correspondence: Raina M Ferzoco Department of Oncology, Mayo Clinic 200 First Street Southwest, Rochester, MN 55905, USA

$\mathrm{Tel}+$ I 50728425 I I

Fax + I 507284 I803

Email ferzoco.raina@mayo.edu 
from postoperative radiation) did not receive it. One-third of men received adjuvant or neoadjuvant chemotherapy, with a trend toward more chemotherapy administration over time. Only $5 \%$ of tumors were positive for HER-2 and $1 \%$ were triple negative for the estrogen receptor, progesterone receptor, and HER-2. Interestingly, although $>90 \%$ of men had hormone receptor positive disease, only $77 \%$ received any adjuvant endocrine therapy. Amongst those who did receive endocrine therapy, tamoxifen monotherapy was utilized in $88 \%$, and aromatase inhibitor was administered alone or in sequence with tamoxifen in $9 \%$.

Most men with estrogen receptor positive early stage breast cancer receive tamoxifen because it is unclear whether aromatase inhibitors adequately reduce their estrogen levels in the absence of concurrent gonadotropin-releasing hormone agonist (GnRH-a) administration. When there is a contraindication to tamoxifen use (eg, a history of pulmonary embolus, though the clot risk associated with tamoxifen is poorly studied in men), aromatase inhibitors are considered with or without GnRH-a. ${ }^{22}$

\section{Surveillance Breast imaging}

Because the age-standardized incidence of male breast cancer is only $1 / 100,000$ person-years with a lifetime risk of $1 / 1,000,{ }^{23-26}$ there is no role for screening breast tissue in the general male population. On the other hand, the risk of a new breast cancer (contralaterally in those who have had mastectomy) is significantly higher in a male breast cancer survivor than in the general population. A study from the Surveillance, Epidemiology, and End Results database that included 1,788 male breast cancers demonstrated a 30 -fold increased risk of developing a contralateral breast cancer (SIR [standardized incidence ratio] $=29.64,95 \%$ CI [confidence interval] 15-52) compared to the general population of men, while female breast cancer survivors only had a two- to fourfold increased risk compared to the general population of women. ${ }^{27}$ This elevated risk was greatest in men who were younger than 50 years when first diagnosed with breast cancer (SIR 110.29, 95\% CI 13.33-401.32). Risk of second breast cancers did not seem to be impacted by receipt of radiation in this study. In a Swedish cohort study that included 457 men with breast cancer, Dong and Hemminki reported a 93-fold (95\% CI 39-84) increased risk of a second breast cancer in men and only a threefold increase in women. The risk was highest in the men in whom $>10$ years had passed since their initial breast cancer diagnosis, but the absolute risk was low $\left(<2 \%\right.$ over a 38 -year follow-up period). ${ }^{28}$ Therefore, it is possible but not certain that routine mammographic imaging of residual breast tissue could be of value in male breast cancer survivors. Male survivors carrying BRCA mutations and those with other conditions known to predispose to new primary cancers (eg, Klinefelter's syndrome) likely have higher rates of future new breast cancers, and therefore could benefit most from breast imaging.

\section{Second cancers}

Male breast cancer survivors are at risk of certain non-breast second malignancies. Cutuli et al reported that $17 \%$ of a cohort of 404 male breast cancer patients later developed at least one other primary malignancy (including prostate, lung, colorectal and esophageal cancers). ${ }^{29} \mathrm{~A}$ recent study by Masci et al revealed that $18 \%$ of male breast cancer survivors developed a second cancer over a median follow-up time of 51.5 months (range: 0.5-219 months), with prostate cancer $(31 \%)$ and colon cancer (19\%) being the most common. Other second neoplasms included gastric cancer, lung cancer, sarcoma, bilateral renal cancer, and leukemia. The median age at diagnosis of the second malignancy was 70 years (range: $54-82$ years). Among the patients in this study who developed second neoplasms, approximately one-half had received anthracycline-based chemotherapy for their breast cancers, approximately three-quarters had received endocrine therapy, and 19\% had undergone adjuvant radiation treatments. However, it is uncertain whether or not a common genetic cause or toxicities of breast cancer treatments contributed to the development of these second cancers. BRCA testing results were not available for the majority of the patients in this study, but it is possible that hereditary cancer syndromes contributed to these findings. The one patient who developed sarcoma after breast cancer was known to carry a BRCA1 mutation. ${ }^{30}$ Interestingly, Auvinen et al reported no increase in nonbreast cancer risk in their analysis of 1,788 male breast cancer patients from the Surveillance, Epidemiology, and End Results registry $(\mathrm{SIR}=0.99,95 \%$ CI $0.86-1.1) .{ }^{27}$

The Swedish cancer database study published by Dong and Hemminki did show a higher risk for second cancers and highlighted that there may be a special link between breast cancer and prostate cancer. ${ }^{28}$ Prostate cancer is the most common malignancy in males, with an incidence that rises with age. Patients with family histories significant for prostate cancer carry an increased risk of breast cancer and vice versa. ${ }^{31,32}$ Also, Thellenberg et al found in another large Swedish cohort study that men previously diagnosed with prostate cancer had a higher risk of breast cancer. ${ }^{33}$ 
This breast-prostate cancer link may be related to $B R C A 2$ mutations and/or to the hormonal milieu, both of which can predispose to both neoplasms. ${ }^{34,35}$

\section{Cancer screening recommendations}

Much remains to be learned about optimal surveillance strategies in men with breast cancer. At this point, we believe that male survivors of early stage breast cancer should be offered the same annual mammography of residual breast tissue for early detection of second breast cancers as female survivors (though the value of breast imaging remains uncertain in men) and the same screening programs for non-breast cancers as men in the general population, unless they are found to carry deleterious genetic mutations for which specific follow-up is recommended.

Extrapolating from National Comprehensive Cancer Network (NCCN) guidelines for female breast cancer survivors, it is likely appropriate to suggest that male breast cancer survivors undergo history and physical examination (including chest wall/breast examination) twice yearly for the first 5 years of surveillance and then annually thereafter. Laboratory testing and nonbreast imaging are recommended only in the setting of clinical suspicion of relapse or recurrence based on new or worsening symptoms. ${ }^{36}$

\section{Importance of genetic counseling and testing in male breast cancer survivors}

Genetic factors play a role in male breast cancer. BRCA mutations, in particular BRCA2 mutations, are significantly associated with male breast cancer. Most population-based studies show that $10 \%-15 \%$ of men with breast cancer carry a mutation in $B R C A 2$. Furthermore, approximately 5\%-10\% of men with $B R C A 2$ mutations will develop breast cancer at some point in their lives. ${ }^{4,37}$ The frequency of these mutations differs drastically among different ethnicities and countries, as some populations carry founder mutations. In Iceland, for instance, the BRCA2 999 del5 founder mutation is seen in over $40 \%$ of male breast cancer cases. ${ }^{38}$ The median age of diagnosis in BRCA2 mutation carriers is 58.8 years, almost a decade younger than that in nonmutation carriers. ${ }^{37}$ There is some evidence that men with $B R C A 2$ mutations who develop breast cancer tend to have more aggressive disease as well. ${ }^{6,37} B R C A 1$ is less closely linked to male breast cancer (multiple series have shown that $<5 \%$ of men with breast cancer carry a BRCA1 mutation). 4,7,37,39,40 Some male BRCA carriers with a history of breast cancer opt for bilateral mastectomies to reduce risk of future breast cancers, but the incidence of ipsilateral and contralateral new primaries remains poorly studied in male survivors with deleterious BRCA mutations.

Mitri et al recently published results that validate the use of BRCAPRO testing in men. ${ }^{44}$ BRCAPRO, which has been validated in other populations, is a model that uses personal cancer history, family cancer history, age at cancer diagnosis, risk-reducing surgery history, ethnicity, and current age or age at death of included individuals to determine risk of carrying a BRCA mutation. ${ }^{41-44}$ This study assessed 148 men, one-third of whom had been diagnosed with breast cancer. Other diagnoses included pancreatic cancer, prostate cancer, and other primary cancers. There were 37 men in the study who did not have a personal history of cancer. Fifty patients $(34 \%)$ tested positive for a BRCA mutation (22 BRCA1, $27 B R C A 2$, and 1 with both $B R C A 1$ and $B R C A 2$ ). The authors found that the median BRCAPRO score was significantly higher for those who tested positive and that the test had appropriate sensitivity, specificity, positive predictive value, and negative predictive value for validation in this population. ${ }^{44}$

Mutations in other genes including CHEK2 and CYP17, have also been implicated in male breast cancer. $C H E K 2$ is a cell cycle checkpoint kinase that contributes to DNA repair. The CHEK2 1100delC mutation is estimated to contribute to $9 \%$ of male breast cancer cases and increases the risk of breast cancer 10-fold in men without BRCA mutations. ${ }^{8,45}$ Mutations in CYP17, a gene involved in the synthesis of estrogen from androgen, have been associated with an increased male breast cancer risk in small studies, but more research is needed in this area. ${ }^{9}$ There has also been at least one case of male breast cancer detected in a carrier of a deleterious mutation in $M L H 1$, a mismatch repair gene. ${ }^{46}$

\section{Genetic testing recommendations}

Owing to the strong link between $B R C A 2$ mutations and male breast cancer, we agree with the $\mathrm{NCCN}$ recommendation that all male breast cancer survivors be offered genetic counseling and testing based on their risk of carrying a deleterious mutation that might be relevant to their own care or the care of their family members. ${ }^{47}$

\section{Managing long-term treatment sequelae Adherence to endocrine therapy}

Men with breast cancer deal with substantial physical, emotional, and social sequelae of this disease. Although the majority of male patients are treated with endocrine therapy because their tumors are usually strongly hormone receptor 
positive, studies have shown that at least $25 \%$ of men discontinue this medication, likely at least in part due to treatment side effects. ${ }^{48-50}$ Visram et al published a retrospective review of 59 male breast cancer patients of whom 42 (71\%) received endocrine therapy. Tamoxifen was used in 38 patients, and their most common side effects were hot flashes, weight gain, decreased libido, fatigue, pulmonary embolism, depression, and rash. Tamoxifen was prematurely discontinued in $24 \%$ of men due to these side effects. Aromatase inhibitors (anastrozole and letrozole) were used in 13 of the 42 patients, and 11 of the 13 had previously taken tamoxifen. Commonly reported side effects of the aromatase inhibitors included decreased libido, peripheral edema, depression, and hot flashes. ${ }^{49}$ Pemmaraju et al published another study evaluating 64 male breast cancer patients on tamoxifen. Thirty-four (53\%) experienced significant side effects, the most common of which were weight gain and sexual dysfunction; $20.3 \%$ of these men discontinued endocrine therapy prematurely. ${ }^{50}$

Thus, it seems in small studies that men with breast cancer who are on endocrine therapy suffer from similar side effects as women who receive these treatments, and are therefore as likely to prematurely discontinue treatment, potentially forfeiting a therapeutic benefit. Although the impact of adjuvant endocrine therapy and lifestyle modifications are only well established in female survivors, it is reasonable to regularly assess adherence to endocrine therapy and to encourage a healthy and active lifestyle (including maintenance of normal body mass index) in male breast cancer survivors. Care providers need to be aware of the side effects of treatment in men in order to offer management strategies and encourage adherence in this population.

\section{Bone health}

The use of aromatase inhibitors in the treatment of breast cancer has been linked to bone loss and fractures in women. ${ }^{51-55}$ As a result, NCCN recommends periodic bone mineral density testing in women on aromatase inhibitor therapy. In contrast, tamoxifen only causes bone thinning in premenopausal women and improves bone density in postmenopausal women. It is unknown how a man's bone density changes during treatment with tamoxifen or aromatase inhibitors. GnRH-a medications, commonly used in the treatment of prostate cancer, have also been linked to increased bone loss and fractures. Multiple studies have shown annual rates of bone loss of $2 \%-8 \%$ in the lumbar spine and $1.8 \%-6.5 \%$ at the femoral neck in men on GnRH-a therapy, ${ }^{56-62}$ with the highest rates of bone loss occurring during the first year of treatment. ${ }^{63,64} \mathrm{GnRH}-\mathrm{a}$ medications have also been associated with an increased risk of fracture. ${ }^{65-67}$ Taylor et al performed a systematic review with a total of 100,000 men on androgen-deprivation therapy and reported a relative risk of skeletal fracture associated with GnRH-a of $1.23(95 \% \mathrm{CI}$ 1.10-1.38) and a relative risk of vertebral fracture associated with GnRH-a of 1.39 (95\% CI 1.20-1.60). ${ }^{68}$ Therefore, the importance of bone mineral density testing in male survivors remains unclear. Recommendations from the National Osteoporosis Foundation (http://www.nof.org) should be followed in this setting (including use of supplemental calcium 1,200 mg daily and vitamin D3 800-1,000 IU daily for all men over age 50). Calculation of a FRAX score may help determine the need for baseline and follow-up dual energy $\mathrm{X}$-ray absorptiometry during adjuvant endocrine therapy for male breast cancer. ${ }^{69}$

\section{Hot flashes}

Hot flash management has been well studied in female breast cancer survivors, but further study is needed in men. Lifestyle modifications such as sleeping in a cool room and dressing in layers may be beneficial, as may medications such as venlafaxine or citalopram..$^{70-73}$ Because $\sim 60 \%-80 \%$ of men with prostate cancer on androgen-deprivation therapy experience hot flashes, the literature on management of hot flashes in prostate cancer may inform recommendations for men with breast cancer. ${ }^{74,75}$ Multiple studies have evaluated venlafaxine, medroxyprogesterone acetate, diethylstilbestrol, and cyproterone acetate in men with prostate cancer, with the most promising results in favor of the hormonal agents (which may decrease the number of hot flashes by $75 \%$ or more). ${ }^{76-82}$ However, because of concerns about the safety of exogenous hormone use in patients with hormonally sensitive tumors, these agents have not been used frequently in male breast cancer survivors.

Acupuncture also appears promising for management of hot flashes in men. Frisk et al assessed the effect of traditional acupuncture versus electrostimulated acupuncture in 29 Swedish men on androgen deprivation for prostate cancer. Both forms of acupuncture significantly decreased the number of hot flashes, distress from hot flashes, and hot flash score (electrostimulated acupuncture $78 \%$ and traditional acupuncture $73 \%$ ) in this population. ${ }^{83} \mathrm{~A}$ larger study intervened with self-acupuncture in 196 men and women (most of whom had prostate or breast cancer) who were experiencing at least 16 hot flashes daily. With selfacupuncture, $79 \%$ of patients experienced at least a $50 \%$ reduction in hot flashes over a mean duration of treatment of 9 months (range: 1 month-6 years). ${ }^{84}$ Therefore, although 
unstudied, acupuncture may be a useful adjunct in the management of hot flashes in men on endocrine therapy for breast cancer.

\section{Sexual dysfunction}

Sexual dysfunction is a significant concern for many male breast cancer survivors. ${ }^{85}$ In a web-based survey, $40 \%$ of 42 respondents, with median age 64 years and median time since diagnosis approximately 2 years, self-reported their sexual functioning over the prior month as very poor on the Expanded Prostate Cancer Index Composite Sexual Scale. Ten percent of these respondents had Stage 4 disease, 62\% had received chemotherapy, and 59\% were on some form of endocrine therapy. Mean Expanded Prostate Cancer Index Composite Sexual Scale scores did not differ significantly between men on or off hormonal therapy, surprisingly. ${ }^{85}$ In addition to the physiological sexual dysfunction that men can experience secondary to their breast cancer treatment, they may also experience significant psychological trauma from their body changes, including loss of breast tissue, testicular changes, and secondary sexual changes that result from the use of hormonal treatments.

Thus, more attention to impotence, poor libido, and other aspects of sexual functioning may be of value to many male breast cancer survivors. This is consistent with the NCCN Survivorship Guidelines, which recommend an open dialog regarding sexual functioning between health care providers and cancer survivors of all types at regular intervals. These guidelines suggest the use of the Sexual Health Inventory for Men, a previously validated five-question survey, in the initial evaluation for erectile dysfunction. ${ }^{86}$ Depending on the severity of the sexual dysfunction, men may try lifestyle modifications, including weight loss, smoking cessation, and decreased alcohol consumption, and/or they may benefit from sexual counseling or phosphodiesterase type 5 inhibitors. Reconstructive surgeries may also be helpful to those who have body image concerns.

\section{Emotional distress}

Because breast cancer is so much more common in women, the emotional burden of this disease may be particularly striking in men. Some men feel embarrassed to have a woman's cancer, and it may be difficult for them to find other male survivors with whom to connect for support. Kipling et al recently published on the psychological impact of breast disorders among males in the UK. Seventy-eight men undergoing workup at a breast clinic in Durham, UK, were surveyed over an 18-month period to assess their feelings about their diagnoses. Almost 30\% of men reported feeling embarrassed to see their doctor and one-fourth reported anxiety related to their diagnosis. ${ }^{87}$

Male breast cancer survivors who are experiencing distress or feeling emasculated may benefit from contact with social workers, psychologists, and male breast cancer support groups. Farrell et al reported on the success of a pilot study evaluating telephone support groups in men with breast cancer. ${ }^{88}$ Eleven men were recruited using flyers in a breast oncology clinic, targeted mailings, and direct referral from their oncologists. A social worker facilitated monthly phone calls for this group, but the topics of discussion were participant driven. Over a course of 6 months, the men discussed sexuality/loss of libido, side effects of treatment, the isolation they felt, how to raise awareness of male breast cancer in their communities, and their frustration regarding the lack of resources for male breast cancer survivors. In response, the social worker engaged a sexual health expert and a medical oncologist to address some of these issues over the phone. Of note, there was no attrition over the course of the support group. On a survey 6 months after the last call, completed by approximately three-fourth of participants, $75 \%$ of the respondents reported that the group allowed them to gain access to new information, connect to others in a similar situation, find mutual support, and feel less alone. Ninety percent of respondents said that they would recommend participation in this type of support group to other men with breast cancer and that it met or exceeded their expectations. ${ }^{88}$ This small pilot study demonstrated that health care providers involved in the care of men with breast cancer can employ creative means to address the psychological, emotional, and sexual sequelae of this rare diagnosis.

\section{Cardiotoxicity}

Cardiac outcomes in male breast cancer survivors are also understudied, but the NCCN survivorship guidelines provide guidance for evaluation and management of the heart after cancer. ${ }^{89}$ Because many men and women with breast cancer are treated with anthracycline and/or HER2-directed therapies, both of which can damage the heart, and because those with at least one heart failure risk factor (hypertension, dyslipidemia, diabetes mellitus, family history of cardiomyopathy, age over 65 years, smoking, alcoholism, obesity, or known cardiovascular comorbidities, including atrial fibrillation, structural heart disease, or coronary artery disease) are at increased risk for progressive heart failure after receipt of anthracyclines, certain male breast cancer survivors may benefit from aggressive cardiovascular risk management with 
the help of a primary care provider and/or a cardiologist. Preliminary research suggests that if anthracycline-related cardiomyopathy is caught early, cardioprotective medications might help optimize long-term cardiac outcomes..$^{90}$ Selected survivors with other cardiovascular risk factors may benefit from consideration of a post-anthracycline echocardiogram. ${ }^{89}$

\section{Venous thromboembolism}

Treatment with tamoxifen is commonly considered an independent risk factor for venous thromboembolism. ${ }^{91,92}$ Data from multiple trials and systematic reviews suggest that the use of tamoxifen for chemoprevention in otherwise healthy women increases the risk of thromboses two- to threefold..$^{93-96}$ This translates to an absolute risk of two to three cases per 1,000 people per year. ${ }^{93,94}$ Venous thromboembolism can be associated with significant morbidity and mortality, with up to $15 \% 3$-month mortality rates in those with pulmonary embolism and up to $70 \%$ post-thrombotic syndrome rates for lower extremity deep venous thromboembolism. ${ }^{97-99}$ Furthermore, multiple population-based studies have demonstrated that the risk of thromboembolism increases exponentially with age. The risk for those younger than 20 years is one in 100,000, for those 40-75 years old is one in 1,000, and for those older than 75 years is 1 in $100 .{ }^{100-102}$ Overall, the age-adjusted annual incidence rate for venous thromboembolism is higher in men $(130 / 100,000)$ compared to that in women $(110 / 100,000)$, except during the childbearing years, when the incidence in women is higher. ${ }^{102-104}$ After age 45 , incidence rates are generally higher in males. ${ }^{103}$ Men on average are diagnosed with breast cancer a decade later than women, so their baseline risk of thromboembolism at the time they start hormonal treatments is higher than that of their female counterparts due to both age and sex. Furthermore, there has been at least one case report of venous thromboembolism as the presenting sign of male breast cancer. ${ }^{105}$ Based on numerous clinical trials and studies in women that demonstrate that tamoxifen is an independent risk factor for venous thromboembolism, we extrapolate that men on tamoxifen are also likely at increased risk for thrombosis and their potential sequelae. Therefore, a careful personal history assessing for risk factors for thromboses and a family history evaluating for thrombophilia should be performed in all men prior to initiation of hormonal therapy. More studies are needed looking at the potentially deadly risk of blood clots in men on hormonal treatment for breast cancer.

\section{Conclusion}

Male breast cancer survivors are a special population. There are no randomized clinical trial data in male breast cancer patients to guide treatment and follow-up recommendations, so we extrapolate from guidelines developed for women with breast cancer and for men with other cancers to outline reasonable follow-up care for male breast cancer survivors. Men are at risk of many of the same treatment-related sequelae as women, and they may suffer a great psychosocial burden from their diagnosis. More research is needed to help tailor therapeutic choices and to increase support for men with breast cancer.

\section{Funding}

This publication was made possible by Clinical and Translational Science Award grant numbers UL1 TR000135 and KL2TR000136-09 from the National Center for Advancing Translational Sciences, a component of the National Institutes of Health. Its contents are solely the responsibility of the authors and do not necessarily represent the official view of National Institutes of Health.

\section{Disclosure}

The authors report no conflicts of interest in this work.

\section{References}

1. Siegel R, Desantis C, Jemal A. Cancer statistics, 2014. CA Cancer J Clin. 2014;64(1):9-29.

2. Giordano SH, Cohen DS, Buzdar AU, Perkins G, Hortobagyi GN. Breast carcinoma in men: a population-based study. Cancer. 2004; 101(1):51-57.

3. Society, AC. Cancer Facts and Figures 2015. Atlanta: American Cancer Society; 2015.

4. Ottini L, Masala G, D'Amico C, et al. BRCA1 and BRCA2 mutation status and tumor characteristics in male breast cancer: a populationbased study in Italy. Cancer Res. 2003;63(2):342-347.

5. Brinton LA, Richesson DA, Gierach GL, et al. Prospective evaluation of risk factors for male breast cancer. J Natl Cancer Inst. 2008; 100(20):1477-1481.

6. Kwiatkowska E, Teresiak M, Filas V, Karczewska A, Breborowicz D, Mackiewicz A. BRCA2 mutations and androgen receptor expression as independent predictors of outcome of male breast cancer patients. Clin Cancer Res. 2003;9(12):4452-4459.

7. Friedman LS, Gayther SA, Kurosaki T, et al. Mutation analysis of BRCA1 and BRCA2 in a male breast cancer population. Am J Hum Genet. 1997;60(2):313-319.

8. Meijers-Heijboer H, van den Ouweland A, Klijn J, et al; Wasielewski M, CHEK2-Breast Cancer Consortium. Low-penetrance susceptibility to breast cancer due to CHEK2 $(*) 1100 \mathrm{delC}$ in noncarriers of BRCA1 or BRCA2 mutations. Nat Genet. 2002;31(1):55-59.

9. Young IE, Kurian KM, Annink C, et al. A polymorphism in the CYP17 gene is associated with male breast cancer. Br J Cancer. 1999;81(1): 141-143.

10. Mester J, Eng C. Cowden syndrome: recognizing and managing a not-so-rare hereditary cancer syndrome. J Surg Oncol. 2015;111(1): $125-130$. 
11. Fackenthal JD, Marsh DJ, Richardson AL, et al. Male breast cancer in Cowden syndrome patients with germline PTEN mutations. J Med Genet. 2001;38(3):159-164.

12. Kuroishi T, Hirose K, Tajima K, Tominaga S. Descriptive epidemiology of male breast cancer in Japan. Breast Cancer. 1997;4(2):77-83.

13. Ron E, Ikeda T, Preston DL, Tokuoka S. Male breast cancer incidence among atomic bomb survivors. J Natl Cancer Inst. 2005;97(8): 603-605.

14. Park S, Kim JH, Koo J, Park BW, Lee KS. Clinicopathological characteristics of male breast cancer. Yonsei Med J. 2008;49(6):978-986.

15. Miao H, Verkooijen HM, Chia KS, et al. Incidence and outcome of male breast cancer: an international population-based study. J Clin Oncol. 2011;29(33):4381-4386.

16. Ewertz M, Holmberg L, Tretli S, Pedersen BV, Kristensen A. Risk factors for male breast cancer - a case-control study from Scandinavia. Acta Oncol. 2001;40(4):467-471.

17. Hultborn R, Hanson C, Köpf I, Verbiené I, Warnhammar E, Weimarck A Prevalence of Klinefelter's syndrome in male breast cancer patients. Anticancer Res. 1997;17(6D):4293-4297.

18. Medras M, Filus A, Jozkow P, Winowski J, Sicinska-Werner T. Breast cancer and long-term hormonal treatment of male hypogonadism. Breast Cancer Res Treat. 2006;96(3):263-265.

19. Cardoso F, Bartlett J, Giordano S. et al. Characterization of male breast cancer: First results of the EORTC10085/TBCRC/BIG/NABCG International Male BC Program. In: 2014 San Antonio Breast Cancer Symposium, 2014, European Organization for Research and Treatment of Cancer, San Antonio, TX.

20. Gnerlich JL, Deshpande AD, Jeffe DB, Seelam S, Kimbuende E, Margenthaler JA. Poorer survival outcomes for male breast cancer compared with female breast cancer may be attributable to in-stage migration. Ann Surg Oncol. 2011;18(7):1837-1844.

21. Howlader N, Noone AM, Krapcho M, et al. editors. SEER Cancer Statistics Review, 1975-2011. Bethesda Maryland: National Cancer Institute; 2014

22. Ruddy KJ, Winer EP. Male breast cancer: risk factors, biology, diagnosis, treatment, and survivorship. Ann Oncol. 2013;24(6):1434-1443.

23. Kiluk JV, Lee MC, Park CK, et al. Male breast cancer: management and follow-up recommendations. Breast J. 2011;17(5):503-509.

24. Sasco AJ, Lowenfels AB, Pasker-de Jong P. Review article: epidemiology of male breast cancer. A meta-analysis of published case-control studies and discussion of selected aetiological factors. Int $J$ Cancer. 1993;53(4):538-549

25. Grenader T, Goldberg A, Shavit L. Second cancers in patients with male breast cancer: a literature review. J Cancer Surviv. 2008;2(2):73-78.

26. Fentiman IS, Fourquet A, Hortobagyi GN. Male breast cancer. Lancet 2006;367(9510):595-604.

27. Auvinen A, Curtis RE, Ron E. Risk of subsequent cancer following breast cancer in men. J Natl Cancer Inst. 2002;94(17):1330-1332.

28. Dong C, Hemminki K. Second primary breast cancer in men. Breast Cancer Res Treat. 2001;66(2):171-172.

29. Cutuli B, Le-Nir CC, Serin D, et al. Male breast cancer. Evolution of treatment and prognostic factors. Analysis of 489 cases. Crit Rev Oncol Hematol. 2010;73(3):246-254.

30. Masci G, Caruso M, Caruso F, et al. Clinicopathological and immunohistochemical characteristics in male breast cancer: a retrospective case series. Oncologist. 2015;20(6):586-592.

31. Anderson DE, Badzioch MD. Familial breast cancer risks. Effects of prostate and other cancers. Cancer. 1993;72(1):114-119.

32. Anderson DE, Badzioch MD. Breast cancer risks in relatives of male breast cancer patients. J Natl Cancer Inst. 1992;84(14): 1114-1117.

33. Thellenberg C, Malmer B, Tavelin B, Grönberg H. Second primary cancers in men with prostate cancer: an increased risk of male breast cancer. J Urol. 2003;169(4):1345-1348.

34. Hemminki K, Scélo G, Boffetta P, et al. Second primary malignancies in patients with male breast cancer. Br J Cancer. 2005;92(7): 1288-1292.
35. Lee UJ, Jones JS. Incidence of prostate cancer in male breast cancer patients: a risk factor for prostate cancer screening. Prostate Cancer Prostatic Dis. 2009;12(1):52-56.

36. Network NCC. Breast Cancer. NCCN Clinical Practice Guidelines in Oncology; 2015. Available from: http://www.nccn.org/professionals/ physician_gls/pdf/breast.pdf. Accessed June 26, 2015.

37. Basham VM, Lipscombe JM, Ward JM, et al. BRCA1 and BRCA2 mutations in a population-based study of male breast cancer. Breast Cancer Res. 2002;4(1):R2.

38. Thorlacius S, Sigurdsson S, Bjarnadottir H, et al. Study of a single BRCA2 mutation with high carrier frequency in a small population. Am J Hum Genet. 1997;60(5):1079-1084.

39. Sverdlov RS, Barshack I, Bar Sade RB, et al. Genetic analyses of male breast cancer in Israel. Genet Test. 2000;4(3):313-317.

40. Giordano SH. A review of the diagnosis and management of male breast cancer. Oncologist. 2005;10(7):471-479.

41. Berry DA, Iversen ES Jr, Gudbjartsson DF, et al. BRCAPRO validation, sensitivity of genetic testing of BRCA1/BRCA2, and prevalence of other breast cancer susceptibility genes. J Clin Oncol. 2002;20(11): 2701-2712.

42. Euhus DM, Smith KC, Robinson L, et al. Pretest prediction of BRCA1 or BRCA2 mutation by risk counselors and the computer model BRCAPRO. J Natl Cancer Inst. 2002;94(11):844-851.

43. Huo D, Senie RT, Daly M, et al. Prediction of BRCA mutations using the BRCAPRO model in clinic-based African American, Hispanic, and other minority families in the United States. J Clin Oncol. 2009;27(8): 1184-1190.

44. Mitri ZI, Jackson M, Garby C, et al. BRCAPRO 6.0 model validation in male patients presenting for BRCA testing. Oncologist. 2015; 20(6):593-597.

45. Neuhausen S, Dunning A, Steele L, et al. Role of CHEK $2 * 1100$ delC in unselected series of non-BRCA1/2 male breast cancers. Int J Cancer. 2004;108(3):477-478.

46. Boyd J, Rhei E, Federici MG, et al. Male breast cancer in the hereditary nonpolyposis colorectal cancer syndrome. Breast Cancer Res Treat. 1999;53(1):87-91.

47. Network NCC. Genetic/Familial High-Risk Assessment: Breast and Ovarian. NCCN Clinical Practice Guidelines in Oncology; 2015. Available from: http://www.nccn.org/professionals/physician_gls/pdf/ genetics_screening.pdf. Accessed June 20, 2015.

48. Anelli TF, Anelli A, Tran KN, Lebwohl DE, Borgen PI. Tamoxifen administration is associated with a high rate of treatment-limiting symptoms in male breast cancer patients. Cancer. 1994;74(1):74-77.

49. Visram H, Kanji F, Dent SF. Endocrine therapy for male breast cancer: rates of toxicity and adherence. Curr Oncol. 2010;17(5):17-21.

50. Pemmaraju N, Munsell MF, Hortobagyi GN, Giordano SH. Retrospective review of male breast cancer patients: analysis of tamoxifen-related side-effects. Ann Oncol. 2012;23(6):1471-1474.

51. Becker T, Lipscombe L, Narod S, Simmons C, Anderson GM, Rochon PA. Systematic review of bone health in older women treated with aromatase inhibitors for early-stage breast cancer. J Am Geriatr Soc. 2012;60(9):1761-1767.

52. Bauer M, Bryce J, Hadji P. Aromatase inhibitor-associated bone loss and its management with bisphosphonates in patients with breast cancer. Breast Cancer. 2012;4:91-101.

53. Eastell R, Adams JE, Coleman RE, et al. Effect of anastrozole on bone mineral density: 5-year results from the anastrozole, tamoxifen, alone or in combination trial 18233230. J Clin Oncol. 2008;26(7):1051-1057.

54. Coleman RE, Banks LM, Girgis SI, et al; Intergroup Exemestane Study Group. Skeletal effects of exemestane on bone-mineral density, bone biomarkers, and fracture incidence in postmenopausal women with early breast cancer participating in the Intergroup Exemestane Study (IES): a randomised controlled study. Lancet Oncol. 2007;8(2):119-127.

55. Howell A, Cuzick J, Baum M, et al; ATAC Trialists' Group. Results of the ATAC (Arimidex, Tamoxifen, Alone or in Combination) trial after completion of 5 years' adjuvant treatment for breast cancer. Lancet. 2005;365(9453):60-62. 
56. Grossmann M, Hamilton EJ, Gilfillan C, Bolton D, Joon DL, Zajac JD. Bone and metabolic health in patients with non-metastatic prostate cancer who are receiving androgen deprivation therapy. Med J Aust. 2011;194(6):301-306.

57. Sharifi N, Gulley JL, Dahut WL. Androgen deprivation therapy for prostate cancer. JAMA. 2005;294(2):238-244.

58. Smith MR. Androgen deprivation therapy for prostate cancer: new concepts and concerns. Curr Opin Endocrinol Diabetes Obes. 2007;14(3):247-254.

59. Greenspan SL. Approach to the prostate cancer patient with bone disease. J Clin Endocrinol Metab. 2008;93(1):2-7.

60. Diamond TH, Higano CS, Smith MR, Guise TA, Singer FR. Osteoporosis in men with prostate carcinoma receiving androgendeprivation therapy: recommendations for diagnosis and therapies. Cancer. 2004;100(5):892-899.

61. Higano CS. Androgen-deprivation-therapy-induced fractures in men with nonmetastatic prostate cancer: what do we really know? Nat Clin Pract Urol. 2008;5(1):24-34.

62. Hamilton EJ, Ghasem-Zadeh A, Gianatti E, et al. Structural decay of bone microarchitecture in men with prostate cancer treated with androgen deprivation therapy. J Clin Endocrinol Metab. 2010;95(12):E456-E463.

63. Greenspan SL, Coates P, Sereika SM, Nelson JB, Trump DL, Resnick NM. Bone loss after initiation of androgen deprivation therapy in patients with prostate cancer. J Clin Endocrinol Metab. 2005;90(12):6410-6417.

64. Morote J, Orsola A, Abascal JM, et al. Bone mineral density changes in patients with prostate cancer during the first 2 years of androgen suppression. $J$ Urol. 2006;175(5):1679-1683. [discussion 1683].

65. Smith MR, Lee WC, Brandman J, Wang Q, Botteman M, Pashos CL. Gonadotropin-releasing hormone agonists and fracture risk: a claimsbased cohort study of men with nonmetastatic prostate cancer. $J$ Clin Oncol. 2005;23(31):7897-7903

66. Smith MR, Boyce SP, Moyneur E, Duh MS, Raut MK, Brandman J. Risk of clinical fractures after gonadotropin-releasing hormone agonist therapy for prostate cancer. J Urol. 2006;175(1):136-139. [discussion 139].

67. Shahinian VB, Kuo YF, Freeman JL, Goodwin JS. Risk of fracture after androgen deprivation for prostate cancer. $N$ Engl J Med. 2005;352(2): 154-164.

68. Taylor LG, Canfield SE, Du XL. Review of major adverse effects of androgen-deprivation therapy in men with prostate cancer. Cancer. 2009;115(11):2388-2399.

69. Network NCC. Prostate Cancer. NCCN Clinical Practice Guidelines in Oncology; 2015. Available from: http://www.nccn.org/professionals/ physician_gls/pdf/prostate.pdf. Accessed July 2, 2015.

70. Bordeleau L, Pritchard KI, Loprinzi CL, et al. Multicenter, randomized, cross-over clinical trial of venlafaxine versus gabapentin for the management of hot flashes in breast cancer survivors. J Clin Oncol. 2010;28(35):5147-5152.

71. Sideras K, Loprinzi CL. Nonhormonal management of hot flashes for women on risk reduction therapy. J Natl Compr Canc Netw. 2010; 8(10):1171-1179

72. Loprinzi CL, Sloan J, Stearns V, et al. Newer antidepressants and gabapentin for hot flashes: an individual patient pooled analysis. J Clin Oncol. 2009;27(17):2831-2837.

73. Loprinzi CL, Barton DL, Sloan JA, et al. Mayo clinic and north central cancer treatment group hot flash studies: a 20-year experience. Menopause. 2008;15(4 pt 1):655-660.

74. Schow DA, Renfer LG, Rozanski TA, Thompson IM. Prevalence of hot flushes during and after neoadjuvant hormonal therapy for localized prostate cancer. South Med J. 1998;91(9):855-857.

75. Karling P, Hammar M, Varenhorst E. Prevalence and duration of hot flushes after surgical or medical castration in men with prostatic carcinoma. J Urol. 1994;152(4):1170-1173.

76. Quella SK, Loprinzi CL, Sloan J, et al. Pilot evaluation of venlafaxine for the treatment of hot flashes in men undergoing androgen ablation therapy for prostate cancer. J Urol. 1999;162(1):98-102.
77. Irani J, Salomon L, Oba R, Bouchard P, Mottet N. Efficacy of venlafaxine, medroxyprogesterone acetate, and cyproterone acetate for the treatment of vasomotor hot flushes in men taking gonadotropin-releasing hormone analogues for prostate cancer: a double-blind, randomised trial. Lancet Oncology. 2010;11(2):147-154.

78. Frisk J. Managing hot flushes in men after prostate cancer - a systematic review. Maturitas. 2010;65(1):15-22.

79. Smith JA Jr. A prospective comparison of treatments for symptomatic hot flushes following endocrine therapy for carcinoma of the prostate. J Urol. 1994;152(1):132-134.

80. Eaton AC, McGuire N. Cyproterone acetate in treatment of postorchidectomy hot flushes. Double-blind cross-over trial. Lancet. 1983;2(8363):1336-1337.

81. Atala A, Amin M, Harty JI. Diethylstilbestrol in treatment of postorchiectomy vasomotor symptoms and its relationship with serum follicle-stimulating hormone, luteinizing hormone, and testosterone. Urology. 1992;39(2):108-110.

82. Loprinzi CL, Michalak JC, Quella SK, et al. Megestrol acetate for the prevention of hot flashes. N Engl J Med. 1994;331(6):347-352.

83. Frisk J, Spetz AC, Hjertberg H, Petersson B, Hammar M. Two modes of acupuncture as a treatment for hot flushes in men with prostate cancer - a prospective multicenter study with long-term follow-up. Eur Urol. 2009;55(1):156-163.

84. Filshie J, Bolton T, Browne D, Ashley S. Acupuncture and self acupuncture for long-term treatment of vasomotor symptoms in cancer patients - audit and treatment algorithm. Acupunct Med. 2005;23(4): 171-180.

85. Ruddy KJ, Giobbie-Hurder A, Giordano SH, et al. Quality of life and symptoms in male breast cancer survivors. Breast. 2013;22(2): 197-199.

86. Cappelleri JC, Rosen RC. The Sexual Health Inventory for Men (SHIM): a 5-year review of research and clinical experience. Int J Impot Res. 2005;17(4):307-319.

87. Kipling M, Ralph JE, Callanan K. Psychological impact of male breast disorders: literature review and survey results. Breast Care. 2014;9(1):29-33.

88. Farrell E, Borstelmann N, Meyer F, Partridge A, Winer E, Ruddy K. Male breast cancer networking and telephone support group: a model for supporting a unique population. Psychooncology. 2014;23(8):956-958.

89. Network NCC. Survivorship. NCCN Clinical Practie Guidelines in Oncology; 2015. Available from: http://www.nccn.org/professionals/ physician_gls/pdf/survivorship.pdf.

90. Cardinale D, Colombo A, Bacchiani G, et al. Early detection of anthracycline cardiotoxicity and improvement with heart failure therapy. Circulation. 2015;131(22):1981-1988.

91. Nevasaari K, Heikkinen M, Taskinen PJ. Tamoxifen and thrombosis. Lancet. 1978;2(8096):946-947.

92. Lipton A, Harvey HA, Hamilton RW. Venous thrombosis as a side effect of tamoxifen treatment. Cancer Treat Rep. 1984;68(6):887-889.

93. Deitcher SR, Gomes MP. The risk of venous thromboembolic disease associated with adjuvant hormone therapy for breast carcinoma: a systematic review. Cancer. 2004;101(3):439-449.

94. Fisher B, Costantino JP, Wickerham DL, et al. Tamoxifen for prevention of breast cancer: report of the National Surgical Adjuvant Breast and Bowel Project P-1 Study. J Natl Cancer Inst. 1998; 90(18):1371-1388.

95. Powles T, Eeles R, Ashley S, et al. Interim analysis of the incidence of breast cancer in the Royal Marsden Hospital tamoxifen randomised chemoprevention trial. Lancet. 1998;352(9122):98-101.

96. Veronesi U, Maisonneuve P, Costa A, et al. Prevention of breast cancer with tamoxifen: preliminary findings from the Italian randomised trial among hysterectomised women. Italian Tamoxifen Prevention Study. Lancet. 1998;352(9122):93-97.

97. Wells PS, Forster AJ. Thrombolysis in deep vein thrombosis: is there still an indication? Thromb Haemost. 2001;86(1):499-508. 
98. Prandoni $\mathrm{P}$, Lensing AW, $\operatorname{Cogo} \mathrm{A}$, et al. The long-term clinical course of acute deep venous thrombosis. Ann Intern Med. 1996; 125(1):1-7.

99. Goldhaber SZ. Pulmonary embolism. N Engl J Med. 1998; 339(2):93-104.

100. Oger E. Incidence of venous thromboembolism: a community-based study in Western France. EPI-GETBP Study Group. Groupe d'Etude de la Thrombose de Bretagne Occidentale. Thromb Haemost. 2000;83(5):657-660.

101. Anderson FA Jr, Wheeler HB, Goldberg RJ, et al. A population-based perspective of the hospital incidence and case-fatality rates of deep vein thrombosis and pulmonary embolism. The Worcester DVT Study. Archives of Internal Medicine. 1991;151(5):933-938.

102. Silverstein MD, Heit JA, Mohr DN, Petterson TM, O'Fallon WM, Melton LJ 3rd. Trends in the incidence of deep vein thrombosis and pulmonary embolism: a 25-year population-based study. Arch Intern Med. 1998;158(6):585-593.
103. Heit JA. Epidemiology of Venous Thromboembolism. Nature reviews. Cardiology. 2015;12:464-474.

104. Naess IA, Christiansen SC, Romundstad P, Cannegieter SC, Rosendaal FR, Hammerstrøm J. Incidence and mortality of venous thrombosis: a population-based study. $J$ Thromb Haemost. 2007; 5(4):692-699.

105. Serra R, Buffone G, Perri P, Renne M, Amato B, de Franciscis S. Male breast cancer manifesting as cephalic vein thrombosis. Ann Vasc Surg. 2013;27(8):e9-e11.

\section{Publish your work in this journal}

Breast Cancer: Targets and Therapy is an international, peerreviewed open access journal focusing on breast cancer research, identification of therapeutic targets and the optimal use of preventative and integrated treatment interventions to achieve improved outcomes, enhanced survival and quality of life for the cancer patient.

\section{Dovepress}

View the full aims and scopes of this journal here. The manuscript management system is completely online and includes a very quick and fair peer-review system, which is all easy to use. Visit http:// www.dovepress.com/testimonials.php to read real quotes from published authors.

Submit your manuscript here: http://www.dovepress.com/breast-cancer---targets-and-therapy-journal 